\title{
ANALYSIS OF GENE ACTION IN THE CONTROL OF BODY WEIGHT IN THE CHICKEN
}

\author{
J. R. MORTON \\ Department of Applied Biology, University of Cambridge
}

Received 18.ix.72

\begin{abstract}
Summary
Gene action and interaction in the control of body weight of chickens at $0,4,8,12,16$ and 20 weeks post-hatching are investigated in the $C H$ and $I A$ inbred lines and crosses between them up to the $\mathbf{S}_{\mathbf{8}}$ and sibbed backcross generations, involving measurements on 1500 cocks and 1626 pullets, spread over 3 years and 14 hatches.

Preliminary analyses concern the removal of hatch and year effects and estimates of the degree of association or dispersion of the size genes in the $\mathrm{CH}$ and $I A$ lines. Hatch/year $\times$ generation interactions were significant in half of the sex $\times$ age combinations, but a simple model removed a significant amount of interaction in nine combinations, removing the significance of the interaction from all except the hatching weights and 4-week male weights. In all sex-age combinations for further analysis, that is 4-week female weights and weights of both sexes beyond that age, genetic dispersion was of the order of 10 per cent.

The main analyses are by least squares equation of generation means to parameters for additive, dominance, maternal and sex-linked effects (additivedominance model); these plus interactions between two loci (digenic interaction model); and all the foregoing plus linkage between the interacting loci (linked digenics model). The additive-dominance model fitted the 4-week female and 20-week male data, but the remaining data were not fitted except by the linked digenics model. There was evidence of maternal and Z-linked effects. The most clear-cut genetic effect was of simple overdominance throughout the data, but there was evidence of duplicate interaction and additive $x$ dominance interaction, these latter varying with age and between sexes.
\end{abstract}

\section{INTRODUCTION}

THE application of the Mather-Hayman method of gene action analysis by the comparison of the means of generations from crosses between inbred lines (e.g. Mather, 1949; Hayman, 1958) to characters in the chicken has not previously been reported except in a brief abstract (Morton, 1964). This paper presents such an analysis of the gene effects on body weight in 4-, 8-, 12-, 16- and 20-week old (post-hatching) chickens. Measurements of hatching weights could not be analysed because of irremovable genotypeenvironment interaction.

\section{Materials AND DATA}

The parental stocks chosen for this experiment were the $C H$ and $I A$ inbred lines of White Leghorns (Pease and Dudley, 1954; Gilmour, 1959). The $I A$ line is singularly small and delicate, having these characteristics to a much greater extent than either a typical White Leghorn or the $C H$ line. Interesting results in the inheritance of body size and conformation had already been found in crosses between these two lines (Cock and Morton, 1963). 
At the start of the experiment the $C H$ line had been sib mated for 25 generations and the $I A$ line for 20 , so that each was theoretically more than 99 per cent. homozygous; but both continued to segregate at a number of blood-group loci (Gilmour, 1959).

The experiment was carried out in the years 1959-1961. Pure lines, the eight possible backcrosses and sibbed backcrosses were bred, as were the reciprocal $S_{1}, S_{2}$ and $S_{3}$ generations (using the notation of Hayman (1953) for the generations equivalent to $F_{1}, F_{2}$ and $F_{3}$ in organisms where only sib mating, not selfing, is possible). The distribution of families of each generation bred in each year is shown in table 1. Birds were hatched fortnightly

TABLE 1

Distribution of dam families in each generation over the three years of the experiment

$\begin{array}{lccc} & 1959 & 1960 & 1961 \\ \text { *C } & 17 & 11 & 17 \\ \mathrm{I} & 8 & 19 & 16 \\ \mathrm{C} \times \mathrm{I} & 25 & - & - \\ \mathrm{I} \times \mathrm{C} & 17 & - & - \\ \mathrm{CI} \times \mathrm{CI} & 15 & 8 & - \\ \mathrm{IC} \times \mathrm{IC} & 16 & 9 & - \\ (\mathrm{CI})^{2} \times(\mathrm{CI})^{2} & - & - & 21 \\ (\mathrm{IC})^{2} \times(\mathrm{IC})^{2} & - & - & - \\ \mathrm{C} \times \mathrm{CI} & 6 & - & - \\ \mathrm{C} \times \mathrm{IC} & 4 & - & - \\ \mathrm{I} \times \mathrm{CI} & 6 & - & - \\ \mathrm{I} \times \mathrm{IC} & 5 & - & - \\ \mathrm{CI} \times \mathrm{C} & 4 & - & - \\ \mathrm{CI} \times \mathrm{I} & 5 & - & - \\ \mathrm{IC} \times \mathrm{C} & 5 & 9 & - \\ \mathrm{IC} \times \mathrm{I} & 4 & 4 & - \\ (\mathrm{C} \times \mathrm{CI})^{2} & - & 6 & - \\ (\mathrm{C} \times \mathrm{IC})^{2} & - & 5 & - \\ (\mathrm{I} \times \mathrm{CI})^{2} & - & 3 & - \\ (\mathrm{I} \times \mathrm{IC})^{2} & - & 4 & - \\ (\mathrm{CI} \times \mathrm{C})^{2} & - & 4 & - \\ (\mathrm{CI} \times \mathrm{I})^{2} & - & - & \end{array}$

* $\mathrm{C}$ used for $C H$ line and I for $I A$ line. The male parent is placed first in each cross. $(\mathrm{CI})^{2}$, etc., are used conventionally for $(\mathrm{C} \times \mathrm{I}) \times(\mathrm{C} \times \mathrm{I})$, etc.

on Wednesdays through Thursdays, the first hatch of each year being in the first week of March. There were five hatches in 1959 and in 1960, but only four in 1961.

The birds were reared in a hot brooder house from 0 to 4 weeks, in a cool brooder house from 4 to 8 weeks and in arks in open range from 8 to 20 weeks. They were fed ad libitum on commercial rations, a chick ration with anti-coccidiostat from 0 to 6 weeks and a range growers ration from 6 to 20 weeks, with the addition of flint grit from 0 to 2 days and small quantities of whole grain from 8 to 20 weeks.

The birds were banded, pedigreed to dam and weighed to the nearest 
$\frac{1}{2} g$ at hatching. Thereafter the 4-weekly weighings were made on Thursday mornings to the nearest gram.

Birds which had any 4-weekly weighing missing, or which, from their failure significantly to gain weight in any 4-week period, were clearly ill, were excluded from the data. A total of 1500 cocks and 1626 pullets remained to enter the analysis. To provide an indication of the size of individual birds, the generation-class means after adjustment for hatch effects (see below) of $C H, I A$ (the smallest) and $\left(I A \sigma \times C H\right.$ ) $\mathrm{S}_{1}$ (the largest) are reproduced in table 2. The generation-class means of newly hatched chicks lay in the range $31-41 \mathrm{~g}$.

\section{TABLE 2}

Class means in grams after adjustment for hatch effects, of the $\mathrm{CH}, \mathrm{IA}$ and (IAO' $\times C H$ O $) S_{1}$ generations from 4 to 20 weeks of age

\begin{tabular}{|c|c|c|c|c|c|c|}
\hline \multirow[b]{2}{*}{ Age (weeks) } & \multicolumn{3}{|c|}{ Males } & \multicolumn{3}{|c|}{ Females } \\
\hline & $\mathrm{CH}$ & $I A$ & $\left(I A_{\sigma^{*}} \times C H\right.$ O $) \mathrm{S}_{1}$ & $\mathrm{CH}$ & $I A$ & $(I A \widetilde{\sigma} \times C H$ 우 $) \mathrm{S}_{1}$ \\
\hline $\begin{array}{r}4 \\
8 \\
12 \\
16 \\
20\end{array}$ & $\begin{array}{r}175 \cdot 0 \\
500 \cdot 6 \\
837.5 \\
1284 \cdot 9 \\
1504 \cdot 7\end{array}$ & $\begin{array}{r}159 \cdot 1 \\
434 \cdot 6 \\
721 \cdot 3 \\
1035 \cdot 4 \\
1287 \cdot 3\end{array}$ & $\begin{array}{r}250 \cdot 3 \\
625 \cdot 3 \\
1125 \cdot 8 \\
1617 \cdot 7 \\
2025 \cdot 9\end{array}$ & $\begin{array}{r}159 \cdot 8 \\
422 \cdot 2 \\
672 \cdot 1 \\
918 \cdot 0 \\
1076 \cdot 7\end{array}$ & $\begin{array}{l}138 \cdot 7 \\
348 \cdot 3 \\
574 \cdot 3 \\
768 \cdot 6 \\
934 \cdot 0\end{array}$ & $\begin{array}{r}217 \cdot 5 \\
516 \cdot 0 \\
928 \cdot 0 \\
1210 \cdot 3 \\
1462 \cdot 8\end{array}$ \\
\hline
\end{tabular}

\section{Preliminary analyses}

\section{(i) Hatch effects}

There were five hatches in each of the years 1959 and 1960 and four in 1961. These were analysed as 14 hatches without regard to year. Analyses of variance were made by the generalised inverse method of generation and hatch effects, and the interaction of generations $\times$ hatches estimated from the residual between-cells variance. As seen from table 3, the hatch effects are in general as great as the generation effects, and both are highly significant even when tested against the interaction where this is found significant compared to the within-cells error variance.

However the existence of a hatch $\times$ generation interaction in most of the measurements would throw doubt on any further analyses of the generation means. Therefore a simple model to remove some interaction effects was fitted. The hatch effects were replaced by three parameters for each hatch, $\mathrm{K}_{1}$ for the effect of that hatch on $C H$ line genes, $\mathrm{K}_{2}$ for $I A$ line genes and $\mathrm{K}_{3}$ for heterozygotes between the genes of the two lines. The analysis was then repeated. The residual variance between cells is now shown in table 3 as "Interaction remaining" and the difference between this residual and that from the previous analysis as "Interaction removed". It will be seen that the interaction removed was significant in nine out of the twelve measures, and that in three out of the six measures that previously showed significant interaction $(\mathrm{G} \times \mathrm{H})$ the remaining interaction is now insignificant. Therefore the main analyses are made on the generation means from this second analysis of those measures which show no remaining interaction, that is 8- to 20-week male and 4- to 20-week female body weights.

The form of the interaction removed is demonstrated by the regressions of $K_{1}$ and $K_{3}$ on the mean of $K_{1}$ and $K_{2}$ (table 4). The regressions are 


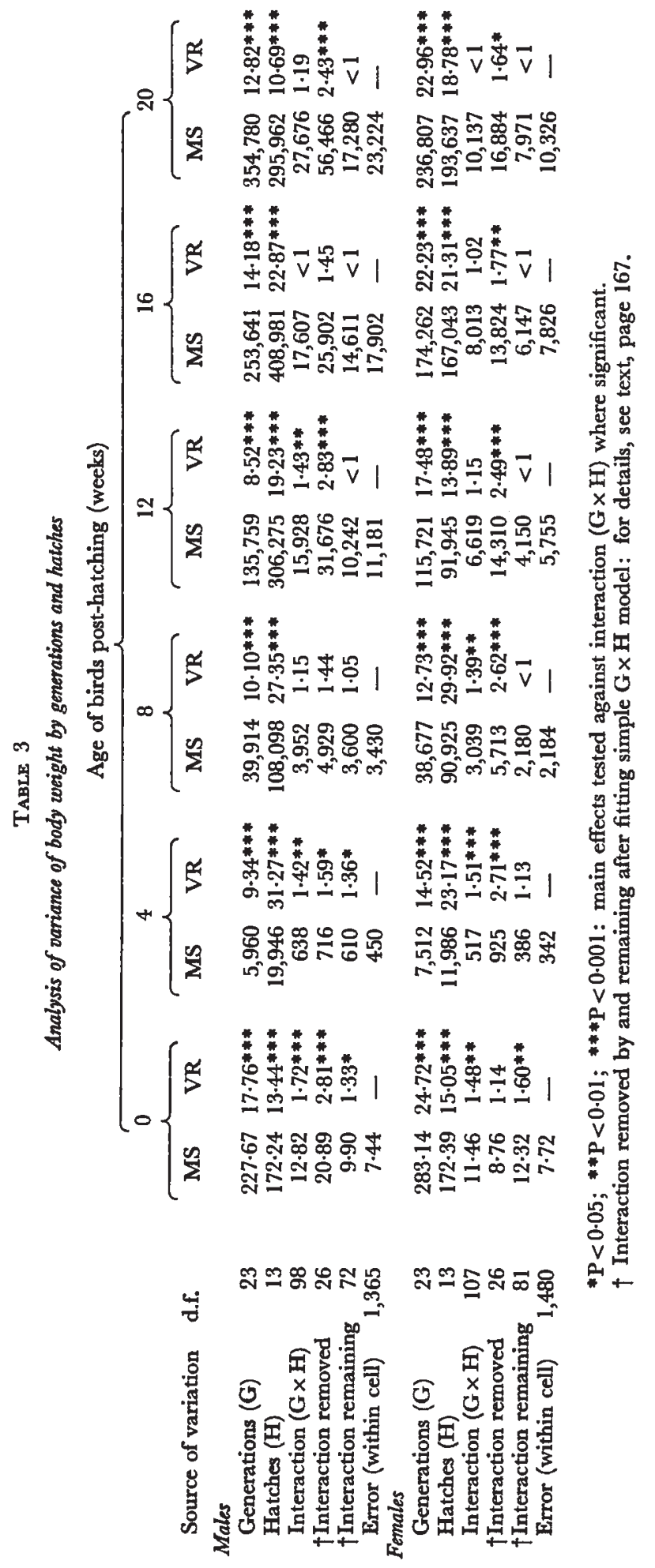


comparable to the tests for genotype $\times$ environment interactions proposed for a similar case by Bucio Alanis, Perkins and Jinks (1969). The regressions of $K_{1}$ on the mean of $K_{1}$ and $K_{2}$ are close to unity suggesting that differential effects of the environment on genes of $C H$ or $I A$ origin were not important in the interaction. But the regressions with $\mathbf{K}_{3}$ as numerator are, except for hatching weight, all negative and significant. The interaction therefore stems from the homeostatic protection of heterozygote genotypes from environmental effects.

\section{(ii) Scaling}

In earlier work on mouse body weights (Morton, 1970), there was evidence of a positive correlation between the means and variances of the backcross generations, suggesting that a logarithmic scale would be appropriate. In chickens, Carte and Siegel (1970) found that the results of a selection experiment for body weight were more comprehensible after such a transformation.

TABLE 4

Regressions of parameter for hatch effects of $\mathrm{CH}$ genes $\left(K_{1}\right)$ and hetero zygotes $\left(K_{8}\right)$ on the mean of $K_{1}$ and $K_{2}$, the parameter for $I A$ line genes

\begin{tabular}{|c|c|c|c|c|c|c|c|}
\hline & & \multicolumn{6}{|c|}{ Age of birds post-hatching (weeks) } \\
\hline & & 0 & 4 & 8 & 12 & 16 & 20 \\
\hline $\begin{array}{l}K_{8} / \frac{1}{2}\left(K_{1}+K_{2}\right) \\
K_{8} / \frac{1}{2}\left(K_{1}+K_{2}\right)\end{array}$ & 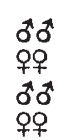 & $\begin{array}{l}+0.832 * \\
+0.762 * * * \\
+0.016 \\
-0.268\end{array}$ & $\begin{array}{l}+0.954 * * * \\
+1 \cdot 109 * * * \\
-1.387 * * * \\
-1 \cdot 689 * * *\end{array}$ & $\begin{array}{l}+0.799 * * * \\
+1.013 * * * \\
-1.153^{*} \\
-1.482 *\end{array}$ & $\begin{array}{l}+1 \cdot 114 * * * \\
+0 \cdot 899 * * * \\
-2 \cdot 428 * * * \\
-2 \cdot 323 * * *\end{array}$ & $\begin{array}{l}+1.244 * * * \\
+1 \cdot 174 * * * \\
-2 \cdot 313 * * * \\
-1.577 *\end{array}$ & $\begin{array}{l}+1.285 * * * \\
+0.970 * * * \\
-2.377 * * * \\
-2.031 * *\end{array}$ \\
\hline
\end{tabular}

However, in the present data there was no evidence of correlations between means and variances. Since, further, the effect of the transformation in the mouse data on the resultant analyses was extremely small (Morton, 1970), the analyses presented here use untransformed data throughout.

\section{(iii) Association and dispersion}

To the extent that the genes for large size are dispersed among the two inbred lines rather than being associated together in the larger $C H$ line, the main analysis by generation means will underestimate additive effects and produce incorrect estimates of additive interaction effects (Jinks and Jones, 1958). An approximate method was used to determine the degree of dispersion from the amount by which the distribution of the $F_{2}$ population lies outside those of the inbred parental populations (Morton, 1970). The advantage of this over the more precise method proposed by Jinks and Perkins (1969), which cannot be used in the present experiment, is that it is calculable before the main analysis. Any bias in the method tends to inflate the estimate of dispersion, and this conservatism is increased by choosing the more variable of the two $\mathrm{S}_{2}$ 's for comparison.

Results of the method for 4- to 20-week body weights of each sex are shown in table 5. With the exception of the 4-week-old males, which cannot be further analysed in any case because of irremovable generation $\times$ hatch interaction, the estimates were all of the order of 10 per cent. It is then 
TABLE 5

Approximate estimates of degree of genetic dispersion $\%$ for body weight from 4 to 20 weeks

$\begin{array}{cccccc} & 4 \text { weeks } & 8 \text { weeks } & 12 \text { weeks } & 16 \text { weeks } & 20 \text { weeks } \\ \text { 우 } & 11 & 6 & 9 & 6 & 13 \\ \text { ช์ } & 19 & 10 & 5 & 11 & 11\end{array}$

most unlikely that dispersion exists to a degree that will vitiate the main analyses.

\section{Main analyses}

\section{(i) Models and method}

The approach to fitting models to the data followed that of Jinks and Perkins (1969), that is to say that the simplest model is fitted first and increasingly complex models thereafter until a satisfactory fit is obtained.

The first two models to be fitted were the additive-dominance and digenic interaction models. Expectations of the generation means for these models can be found in Van der Veen (1959), if it is recalled that the expectation of the means of the $S_{1}$ and $S_{2}$ are the same as those of the $F_{1}$ and $F_{2}$, of the $S_{3}$ as those of the $\mathrm{F}_{2}$ bip, and of sibbed backcrosses as the two Bbip. But it is well known that sex-linkage and maternal effects are commonly important in the chicken (Cock and Morton, 1963). Additional parameters are needed for these.

It is necessary that the parameters for sex-linkage be clearly defined, and that the definitions represent the situation in the organism concerned and lead to mathematical solutions. Here, as in the previous experiment with mice (Morton, 1970) the sexes are to be analysed separately. In the mouse experiment, the X-linked parameter was defined by giving the value of +1 to a $C B A \mathrm{X}$ chromosome and -1 to an $A \mathrm{X}$ chromosome, while the $\mathrm{Y}$ linked parameter was defined as the effect of a $C B A$ Y chromosome relative to an $A \mathrm{Y}$ chromosome, and the parameters inserted allowing for the fact that one random $\mathrm{X}$ chromosome is inactivated in the female mammal (Lyon, 1962). In this present experiment two of the three parameters are defined analogously, " $z$ " taking the value +1 for a $C H \mathrm{Z}$ chromosome and -1 for an $I A \mathrm{Z}$ chromosome and " $w$ " taking the value +1 for a $C H \mathrm{~W}$ chromosome and zero for an $I A \mathrm{~W}$ chromosome. However, in the chicken there is no dosage compensation in the homogametic (male) sex (Cock, 1953), and a further parameter $(z h)$ for average heterosis between genes on the $C H$ and $I A \mathrm{Z}$ chromosomes is needed (cf. Mather and Jinks, 1963). The distribution of coefficients of the three parameters among the seven basic sex-chromosome genotypes is, by these definitions:

\begin{tabular}{lccc}
\multicolumn{4}{c}{ Male genotypes } \\
$\overbrace{z}^{C H} \mathrm{Z}^{C H}$ & $\mathrm{Z}^{C H} \mathrm{Z}^{I A}$ & $\mathrm{Z}^{I_{A}} \mathrm{Z}^{I A}$ \\
$z h$ & +2 & 0 & -2 \\
$w$ & 0 & +1 & 0 \\
& 0 & 0 & 0
\end{tabular}

\begin{tabular}{|c|c|c|c|}
\hline \multicolumn{4}{|c|}{ Female genotypes } \\
\hline $\mathrm{Z}^{C H} \mathrm{~W}^{C H}$ & $\mathrm{Z}^{C H} \mathrm{~W}^{1 \mathrm{~A}}$ & $\mathrm{Z}^{I A} \mathrm{~W}^{C H}$ & $\mathrm{Z}^{I A} \mathrm{~W}^{I A}$ \\
\hline $\begin{array}{r}+1 \\
0 \\
+1\end{array}$ & $\begin{array}{r}+1 \\
0 \\
0\end{array}$ & $\begin{array}{r}-1 \\
0 \\
+1\end{array}$ & $\begin{array}{r}-1 \\
0 \\
0\end{array}$ \\
\hline
\end{tabular}

The digenic interaction model then consists in 13 parameters, 12 of which 
are applicable to each sex, namely, $m=$ notional mean, and deviations from this mean as follows:

$$
\begin{aligned}
d & =\text { additive } \\
h & =\text { dominance } \\
i & =\text { additive } \times \text { additive } \\
j & =\text { additive } \times \text { dominance } \\
l & =\text { dominance } \times \text { dominance } \\
n & =C H \text { dam maternal }
\end{aligned}
$$

$$
\begin{aligned}
& r=I A \text { dam maternal } \\
& s=\left(C H \text { 우 } \times I A \delta^{\jmath}\right) \mathrm{S}_{1} \text { dam maternal } \\
& q=\left(I A{ }^{\circ} \times C H_{\delta}\right) \mathrm{S}_{1} \text { dam maternal } \\
& z=\mathrm{Z} \text { chromosomal } \\
& z h=\text { homogametic heterotic } \\
& w=W \text { chromosomal }
\end{aligned}
$$

The additive-dominance model is identical except for the omission of the terms " $i$ ", " $j$ " and " $l$ ".

Where neither of these models provided a satisfactory fit to the data, two approaches were tried. The period weight gains between weighings, rather than the weight for age data, were analysed, to see whether this simplified the genetic effects. And a model for linkage with digenic interaction was fitted. This model is based on that given in Jinks and Perkins (1969), but differs in two respects.

Firstly, it was necessary because of the use of parameters for sex-linkage, to calculate the expectation for the $F_{2}$ bip, equivalent here to the $S_{3}$ generation, which is not given by Jinks and Perkins (1969). It was found that by algebraic rearrangement the terms in $p^{3}$, where $p$ is the recombination fraction, in the gametic frequencies could be made to cancel out, so that the terms in $p^{3} i, p^{5} l$ and $p^{6} l$, which led Jinks and Perkins to omit this expectation, no longer occur. The expectation of this generation is then

$$
\mathscr{E} \overline{\mathrm{S}}_{3}=\mathscr{E} \mathrm{F}_{2} \mathrm{bip}=\frac{1}{2}(m+h+l)+\frac{1}{2}(m+i)-\frac{3}{2} p i+p^{2} i-\frac{8}{2} p l+\frac{13}{4} p^{3} l-3 p^{2} l+p^{4} l .
$$

Secondly, the generations available do not allow the separate estimation of each of the parameters concerned with linkage and digenic interaction. The expectations of $p i$ and $p l$ are identical in each generation, and the three parameters, $p^{2} i, p^{3} l$ and $p^{4} l$, are found in the expectation of only the $\mathrm{S}_{8}$ and sibbed backcrosses (equivalent to $B_{1}$ bip and $B_{2}$ bip) and their coefficients in the latter are identical. Therefore these five parameters were replaced by three joint parameters, $(p i+p l),\left(p^{2} i-p^{8} l\right)$ and $\left(p^{4} l-2 p^{8} l\right)$.

The same parameters as used in the earlier models for sex-linked and maternal effects were added to the linkage model, except that the earlier analyses having shown that the $\left(I A O \times C H H^{\top}\right) \mathrm{S}_{1}$ dams had no effects even approaching significance, the relevant parameter, " $q$ ", was dropped.

For each model the sexes are analysed separately. The 9,12 or 14 parameters are estimated from the means of the 24 generations (table 1), by weighted least squares and a $\chi^{2}$ test for goodness of fit of the model made, following Cavalli (1952).

In the least squares solutions, the weights applied to each equation should ideally be the reciprocal of the variances attributable to each generation mean estimated from a minimum of 100 individuals per generation (Jinks and Perkins, 1969). In the present data, only the four $\mathrm{S}_{2}$ and $\mathrm{S}_{3}$ generations contained more than 100 observations in each sex, and some of the backcross and sibbed backcross generation means were based on many less individuals. The generation $\times$ hatch analyses described earlier p. (167) had been designed to yield standard errors for the generation means based on the overall within 
cell variance, the error variance derived from the hatch and hatch $\times$ generation interaction corrections and the number of birds per generation. The squared reciprocals of these standard errors were used as weights in the belief that the resultant loss of maximum likelihood was less serious than the possibility of inaccurate estimates of the variances of individual generation means due to small numbers. These weights are not applicable if correction for hatch and generation $\times$ hatch $(\mathrm{G} \times \mathrm{H})$ interaction is incomplete. For this reason, and because of doubts as to the results of an analysis performed on data with residual $\mathrm{G} \times \mathrm{H}$ interaction, hatching weights in both sexes and 4-week weights in males were omitted from the analysis. The models were therefore fitted to the generation means, adjusted for hatch and hatch $x$ generation interaction effects, for 4- to 20-week female and 8- to 20-week male body weights.

The generation class means for the gain in weight from 4 to 8 and 4 to 12 weeks in females, and 8 to 12,12 to 16,16 to 20 and 12 to 20 weeks in both sexes, were calculated from the data adjusted for hatch and hatch $\times$ generation interaction effects. Also calculated were the variances within each generation and within all generations after adjustment. The weights for the least squares analyses of these data were therefore derived from the variances within the $S_{2}$ and $S_{3}$ generations, since these were each represented by more than 100 individual values, but for the remaining generations, the larger of the variance within the relevant generation and the variance within all generations was chosen. In this way any possibility of finding false significant results from over large weights estimated from too few individuals is avoided.

Estimates of the standard errors of the parameters were initially calculated from the appropriate combination of the error variances within generation means. Where, however, the $\chi^{2}$ for goodness of fit remained significant, they were corrected by multiplication by $\sqrt{\frac{\chi^{2}}{v}}$, where $v$ is the number of degrees of freedom of the $\chi^{2}$ and hence of the $t$-test for significance of the parameters.

\section{(ii) Fit of models}

The additive-dominance model was fitted first to the 4-week female data, and the 8-, 12-, 16- and 20-week data of both sexes. The results of the $\chi^{2}$ tests for goodness of fit are shown in the first two rows of table 6 . The genetic control of only 4 -week female weight and 20 -week male weight could successfully be explained by this model, but the tests showed a contrast between the two sexes in that, with increasing age, the model provided an increasingly poor fit to the female but an increasingly good one to the male data. Fitting of the digenic interaction model to the same data produced no real improvement of fit except to the weight of 8-week old males (third and fourth rows of table 6). Further, the only parameters which could be shown to be significant in these analyses were " $h$ ", the dominance deviation and " $s$ ", the maternal effect of one of the $S_{1}$ 's. Thus there was no evidence for the effect of digenic interaction between unlinked loci.

At this stage, it was decided to note the individual contributions of each generation to the overall $\chi^{2}$ as a guide to which further analyses might be profitable. The generations least well fitted were certain of the sibbed backcrosses and, in particular, the $S_{3}$ 's. Contrary to the two models thus far 
tested, which predict no change in the mean between the $S_{2}$ and $S_{3}$, the fall in body weights from $S_{2}$ to $S_{3}$ was greater than from backcross to sibbed backcross. Two explanations presented themselves, more complex maternal effects, and the effects of linkage on digenic interaction. There is a limit to the number of parameters for maternal effects that can be fitted and, further, almost any model can be fitted to almost any data by the specification of arbitrary maternal effects. Therefore this first explanation was approached by analysing the growth increments between weighings in the belief that this might remove some maternal effects. The results are shown in rows 7 and 8 of table 6. Clearly the fit of the digenic interaction model to the period weight gains is even less satisfactory than the fit to the actual weights at different ages.

TABLe 6

$\chi^{2}$ tests for goodness of fit of models

\begin{tabular}{|c|c|c|c|c|c|c|c|c|}
\hline \multirow{2}{*}{$\begin{array}{l}\text { Weight for age } \\
\text { Model }\end{array}$} & \multirow[b]{2}{*}{ d.f. } & \multirow[b]{2}{*}{ Sex } & \multicolumn{5}{|c|}{ Age (weeks) } & \\
\hline & & & 4 & 8 & 12 & 16 & 20 & \\
\hline Additive-dominance & 15 & 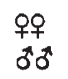 & 18.05 & $\begin{array}{l}26 \cdot 25^{*} \\
36 \cdot 46^{* * *}\end{array}$ & $\begin{array}{l}52 \cdot 42 * * * \\
33 \cdot 15^{* *}\end{array}$ & $\begin{array}{l}53 \cdot 86^{* * *} \\
28.95^{*}\end{array}$ & $\begin{array}{l}69 \cdot 94 * * * \\
9 \cdot 74\end{array}$ & \\
\hline Digenic interactions & 12 & 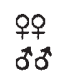 & $15 \cdot 54$ & $\begin{array}{l}21 \cdot 78^{*} \\
26 \cdot 00^{*}\end{array}$ & $\begin{array}{l}48 \cdot 11^{* * *} \\
27 \cdot 63^{* *}\end{array}$ & $\begin{array}{l}45 \cdot 54 * * * \\
28 \cdot 35 * *\end{array}$ & $\begin{array}{l}60 \cdot 55^{* * *} \\
7 \cdot 75\end{array}$ & \\
\hline \multirow[t]{2}{*}{ Linked digenics } & 10 & 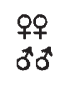 & $12 \cdot 15$ & $\begin{array}{l}7 \cdot 00 \\
9 \cdot 17\end{array}$ & $\begin{array}{l}9.56 \\
6.90\end{array}$ & $\begin{array}{l}7 \cdot 03 \\
4 \cdot 26\end{array}$ & $\begin{array}{l}6 \cdot 80 \\
2 \cdot 70\end{array}$ & \\
\hline & & & \multicolumn{6}{|c|}{ Period (weeks) } \\
\hline $\begin{array}{l}\text { Period weight gains } \\
\text { Model }\end{array}$ & d.f. & Sex & $4-8$ & $4-12$ & $8-12$ & $12-16$ & $12-20$ & $16-20$ \\
\hline Digenic interactions & 12 & 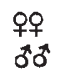 & $125 \cdot 44 * * *$ & $290 \cdot 24 * * *$ & $\begin{array}{r}241 \cdot 28 * * * * \\
96 \cdot 49 * * *\end{array}$ & $\begin{array}{l}33 \cdot 76 * * * \\
43 \cdot 84^{* * * *}\end{array}$ & $\begin{array}{r}131 \cdot 96^{* * *} \\
27 \cdot 24^{* * * *}\end{array}$ & $\begin{array}{l}113 \cdot 78^{* * *} \\
158 \cdot 20^{* * *}\end{array}$ \\
\hline Linked digenics & 10 & $\begin{array}{l}\text { 우 } \\
\text { ठำ }\end{array}$ & 14.56 & $19 \cdot 31^{*}$ & $\begin{array}{l}19 \cdot 03^{*} \\
15 \cdot 70\end{array}$ & $\begin{array}{r}14 \cdot 34 \\
9 \cdot 01\end{array}$ & $\begin{array}{r}13 \cdot 16 \\
8 \cdot 87\end{array}$ & $\begin{array}{r}8 \cdot 59 \\
12 \cdot 90\end{array}$ \\
\hline
\end{tabular}

There remained to test the digenic interaction model with linkage in which the number of parameters involving linkage had to be reduced because of the confounding of their estimators, and from which " $q$ ", the maternal effect of the $\left(I A\right.$ 우 $\left.\times C H_{\circlearrowleft}\right) \mathrm{S}_{1}$ dams, was dropped, as explained above. The fit of this model to the weight-for-age data is perfect (rows 5 and 6 of table 6). Since the increments between weighings had been extracted, the linked digenic model was fitted to these also, and, as is shown in rows 9 and 10 of table 6 , the fit was again perfect except for just significant $\chi^{2}$ 's in 4 to 12 and 8 to 12 weeks in females.

\section{(iii) Estimates of the parameters}

From table 6 it is clear that the linked digenics model provides the best fit to all data, except 4-week female and 20-week male data which are sufficiently explained by the additive-dominance model. The parameter estimates for these latter are shown in table 7 . Both cases show the greatest 


\section{Table 7}

Estimates (in grams) of the parameters of the additive-dominance model for the weight of 4-week females and 20-week males

$\begin{array}{lcc} & \text { 4-week } & \text { 20-week } \\ & \text { \%ᄋ } & \delta^{*} \sigma^{*} \\ m & 168 & 1337 \\ d & +28^{* *} & +46 \\ h & +60^{* * *} & +475^{* * *} \\ n & -12^{* *} & +110^{* * *} \\ r & -11^{* *} & -9 \\ s & +9 * & +35 \\ q & -6 & +7 \\ z & -12^{*} & +1 \\ z h & -10 & +49 \\ w & -10 & -\end{array}$

Table 8

Estimates (in grams) of the parameters of the linked digenics model for weight at different ages

\begin{tabular}{|c|c|c|c|c|}
\hline \multirow[b]{2}{*}{$\begin{array}{l}\text { Parameter } \\
\text { 우 }\end{array}$} & \multicolumn{4}{|c|}{ Age (weeks) } \\
\hline & 8 & 12 & 16 & 20 \\
\hline$d$ & 53 & 95 & 100 & 68 \\
\hline$m+h+l$ & $490 * * *$ & $880 * * *$ & $1154 * * *$ & $1407 * * *$ \\
\hline$m+i$ & $385 * * *$ & $619 * * *$ & $829 * * *$ & $1006 * * *$ \\
\hline$p i+p l$ & -40 & -46 & -68 & -57 \\
\hline$p^{2} i-p^{3} l$ & 32 & $164 * *$ & $222 *$ & $271 * * *$ \\
\hline$p j$ & -8 & 8 & 23 & -15 \\
\hline$p^{2} j$ & -4 & -18 & -26 & $-159^{*}$ \\
\hline$p^{2} l$ & -12 & -13 & -29 & -33 \\
\hline$p^{4} l-2 p^{3} l$ & $-69 *$ & $-246 * * *$ & $-287 * * *$ & $-361 * * *$ \\
\hline$n$ & 12 & 21 & 41 & 34 \\
\hline$r$ & -2 & 11 & 11 & -23 \\
\hline$s$ & 22 & 43 & 46 & 33 \\
\hline$z$ & -19 & -39 & -28 & -19 \\
\hline$w$ & -10 & -24 & -24 & -12 \\
\hline$\sigma^{x} \sigma^{x}$ & & & & \\
\hline$d$ & 21 & 36 & 53 & \\
\hline$m+h+l$ & $556 * * *$ & $1045 * * *$ & $1518 * * *$ & \\
\hline$m+i$ & $448 * * *$ & $750 * * *$ & $1100 * * *$ & \\
\hline$p i+p l$ & $-91 *$ & $-108 *$ & -8 & \\
\hline$p^{2} i-p^{3} l$ & 50 & 103 & 105 & \\
\hline$p j$ & -19 & -48 & -43 & \\
\hline$p^{2} j$ & -41 & -112 & -212 & \\
\hline$p^{2} l$ & -37 & -29 & 17 & \\
\hline$p^{2} l-2 p^{3} l$ & -82 & $-214 * *$ & $-303 * *$ & \\
\hline$n$ & 31 & 60 & 67 & \\
\hline$r$ & 8 & 0 & -27 & \\
\hline$s$ & 23 & 30 & 27 & \\
\hline$z$ & 0 & -4 & -7 & \\
\hline$z h$ & 25 & 21 & 28 & \\
\hline
\end{tabular}


effect of " $h$ ", the dominance deviation, in increasing body size, but otherwise they differ. In 20-week males the only other significant effect is a considerable boost to body weight from having a $C H$ line dam. In the 4-week female data, both pure line dams suppress weight while the $\left(C H\right.$ ㅇ $\left.\times I A_{0}\right) \mathrm{S}_{1}$ dam increases it, and autosomal genes of the $C H$ line increase weight but sex-linked genes of that line decrease it.

The parameter estimates for the linked digenics model are given in table 8 for weight-for-age data and in table 9 for the 4-week weight increments. In

TABLE 9

Estimates (in grams) of the parameters of the linked digenic model for weight gains in age intervals

\begin{tabular}{|c|c|c|c|c|c|c|}
\hline \multirow[b]{2}{*}{$\begin{array}{l}\text { Parameters } \\
\text { 우 }\end{array}$} & \multicolumn{6}{|c|}{ Age intervals (weeks) } \\
\hline & $4-8$ & $4-12$ & $8-12$ & $12-16$ & $12-20$ & $16-20$ \\
\hline$d$ & 27 & 66 & $\begin{array}{l}36 \\
388 * * *\end{array}$ & 19 & $\begin{array}{c}5 \\
508 * * *\end{array}$ & -17 \\
\hline $\begin{array}{c}m+h+l \\
m+i\end{array}$ & $\begin{array}{l}274^{* * *} \\
228 * * *\end{array}$ & $\begin{array}{l}662 * * * \\
461 * * *\end{array}$ & $\begin{array}{l}388 * * * \\
234 * * *\end{array}$ & $275^{* * *}$ & $\begin{array}{l}528 * * * \\
387 * * *\end{array}$ & $\begin{array}{l}254 * * * \\
177^{* * *}\end{array}$ \\
\hline $\begin{array}{l}m+i \\
b i+p l\end{array}$ & $\begin{array}{l}228 * \cdots * \\
-29 * *\end{array}$ & $\begin{array}{l}401.40 \\
-37\end{array}$ & $\begin{array}{l}234 \cdots \\
-6\end{array}$ & $\begin{array}{l}2110+4 \\
-18\end{array}$ & $\begin{array}{l}38 / 6 \\
-13\end{array}$ & $177 * * *$ \\
\hline $\begin{array}{r}p i+p l \\
p^{2} i-p^{2} l\end{array}$ & $\begin{array}{l}-29+4 \\
-4\end{array}$ & $137 * * *$ & $138 * * *$ & $55 * *$ & $111 * * *$ & $\begin{array}{l}11 \\
58 * *\end{array}$ \\
\hline$\not j j$ & -7 & 13 & 20 & 11 & $-23^{*}$ & $-37 * * *$ \\
\hline$p^{2} j$ & 1 & -22 & -23 & 5 & $-116 * * *$ & $-123 * * *$ \\
\hline$p^{2 l}$ & -6 & -7 & -1 & -14 & $-21 *$ & -4 \\
\hline$p^{2} l-2 p^{3} l$ & $-41 * *$ & $-224 * * *$ & $-181 * * *$ & $-42^{*}$ & $-116^{* * *}$ & $-80 * * *$ \\
\hline$n$ & $15^{*}$ & 34 & 18 & 7 & 2 & -8 \\
\hline$r$ & 1 & 12 & 8 & 7 & -18 & $-28^{*}$ \\
\hline$s$ & 6 & 31 & 24 & 1 & -7 & -9 \\
\hline$z$ & -8 & -30 & -20 & 5 & 4 & 1 \\
\hline$w$ & 0 & -19 & -17 & 3 & 8 & 6 \\
\hline $0^{7} 0^{*}$ & & & & & & \\
\hline$\frac{d}{m+h+l}$ & & & $\begin{array}{l}28 * \\
496 * * *\end{array}$ & $\stackrel{2}{459 * * *}$ & $\begin{array}{c}4 \\
839 * * *\end{array}$ & $\begin{array}{c}3 \\
379^{* * *}\end{array}$ \\
\hline$m+i$ & & & $305^{* * *}$ & $346 * * *$ & $617 * * *$ & $271 * * *$ \\
\hline$p i+p l$ & & & -14 & $102 * * *$ & $213^{* * *}$ & $114 * * *$ \\
\hline$p^{2} i-p^{3} l$ & & & 42 & 15 & -28 & -44 \\
\hline$\not p j$ & & & $-32^{*}$ & 12 & 31 & 18 \\
\hline$p^{2} j$ & & & $-60 *$ & $-101^{* * *}$ & 49 & $148 * * *$ \\
\hline$p^{2} l$ & & & 9 & $46 * * *$ & $89 * * *$ & $46 * * *$ \\
\hline$p^{2} l-2 p^{3} l$ & & & $-126 * * *$ & $-91 * * *$ & -13 & $75 * *$ \\
\hline$n$ & & & 17 & 14 & 31 & 16 \\
\hline r & & & -3 & $-25^{*}$ & -32 & -7 \\
\hline $\boldsymbol{s}$ & & & 2 & 12 & 7 & -5 \\
\hline$z$ & & & -7 & 2 & 7 & 5 \\
\hline zh & & & -6 & 17 & 3 & 17 \\
\hline
\end{tabular}

$* \mathrm{P}<0.05 ; * * \mathrm{P}<0.01 ; * * * \mathrm{P}<0.001$.

each case " $m+h+l$ " is considerably greater than " $m+i$ ". Since the estimates of these two compound parameters were approximately ten times their standard errors throughout, the differences are clearly significant without further statistical tests. The differences, whether expressed as a percentage of " $m+i$ " or of " $m+h+l$ " are smaller in both sexes at 8 weeks of age than thereafter, and, as would be expected, greater in each sex in the 8- to 12 week period of growth than any other. Since in the other analyses " $h$ " was always large and positive and usually significant, it no doubt accounts for 
much of this difference. The only data in which " $d$ ", the additive effect, is significant is the 8- to 12-week increment in males.

For the parameters containing " $p$ ", the recombination fraction, the pattern is simpler in the females. The estimate of " $p^{4} l-2 p^{3} l$ " is negative throughout female growth and increasingly negative in the weight-for-age results. That of " $p^{2} i-p^{3} l$ " is positive in growth intervals from 8 weeks onwards and increasingly positive in the weight-for-age results from that point. The estimates of " $p j$ " and " $p^{2} j$ " are significantly negative in the growth periods to 20 weeks, at which age weight is affected by a significant negative effect of " $p^{2} j$ " but only in a change of sign between non-significant estimates of " $p j "$ ". In the more complex male results can be seen a change from significantly negative to significantly positive estimates for " $p$ " $j$ " and " $p^{4} l-2 p^{3} l "$ in the growth intervals either side of 16 weeks of age, and a change from effectively no effect to significantly positive estimates of " $p i+p l$ " and " $p^{2} l$ " in the growth results beyond 12 weeks of age. These latter two estimates are significantly negative in 8-week-old males, but are effectively zero by 16 weeks, while " $p^{2} j$ " and " $p^{4} l-2 p^{3} l$ " become increasingly negative to 16 weeks of age when they are counteracted by the positive effects in the 16 to 20 -week growth period. It is then clear how these effects in the males cancel out so that 20 -week male body weight can be represented by the simple additive-dominance model. The genetic meaning of these results will be further considered in the Discussion.

In tables 8 and 9, there are few significant results for sex-linkage or maternal effects. The $C H$ line dam causes some increase in 4-8 week growth in females, and the $I A$ line dam suppresses growth between 12 and 16 weeks in males and between 16 and 20 weeks in females.

\section{Discussion}

Although few of the maternal and sex-linked effects were significant, there was sufficient consistency in the results for some of them to be accepted as real. The $C H$ line dam, after depressing 4-week female weight, boosted 4to 8-week female weight gain, caused a highly significant increase in 20-week male weight and was positive for all weights at 8 weeks and over and most increments between weighings. The $I A$ line dam depressed not only 4-week female weight but also growth between 12 and 16 weeks in males and between 16 and 20 weeks in females. The $\left(C H\right.$ 우 $\left.\times I A \sigma^{*}\right) \mathrm{S}_{1}$ dam increased 4-week female weight while its reciprocal did not, although the eggs of the former are about $1 \frac{1}{2} \mathrm{~g}$. smaller than those of the latter; this effect seemed to continue, although not significantly, through all later ages. The effect of the $C H \mathrm{Z}$ chromosome depressed body weight compared to the $I A \mathrm{Z}$ chromozome in females of 4 weeks of age, and the effect appeared to continue, at least in females, throughout the growing period.

Cock and Morton (1963) reviewed the results on sex-linkage and maternal effects in chickens that had been published at that time, and found them inconclusive and in many instances difficult of interpretation because of the forms of analysis used. In the results reported in that paper, which included the 20-week $S_{1}$ and $S_{2}$ body weight data which were used in the present paper, we concluded that the $C H$ line dams increased body size relative to $I A$ dams, but that the $\mathrm{CH}$ line $\mathrm{Z}$ chromosome reduced body weight, which agrees with the present results. More recently Buvanendran (1967) analysed a reciprocal 
cross between the White Rock and Cornish breeds for weight at 6, 8, 10 and 12 weeks of age by the same method as Cock and Morton (1963). He found that the smaller White Rock females exerted a maternal effect which increased size by about 8 per cent. at all ages, and that the $Z$ chromosome of the Cornish breed increased the weights by about $3 \frac{1}{2}$ per cent. relative to the $\mathrm{Z}$ chromosome of the White Rock breed. Clearly it is not possible from the body size or egg size of the parents to predict the effect of using any one cross rather than its reciprocal.

Interpretation of the genetic meaning of the results is difficult because the generations available permitted the estimation of so few of the parameters singly, and is further complicated by the nature of the results themselves. For example, since by definition $0<P<\frac{1}{2}$, " $p^{2} j$ " must be smaller absolutely than " $p j$ " and " $p^{4} l-2 p^{3} l$ " must be smaller and of opposite sign to " $p 2 l$ ", but in most of the analyses the opposite is true. A similar, although less complex, problem is found in the results of Jinks and Perkins (1969) with height in Nicotiana, where the estimates showed " $p^{2} i ">$ " $p i ">0$, " $p^{2} j "<" p j "<0$ and " $p^{4} l "<" p^{3} l "<" p^{2} l$ " $<" p l "<0$. Some attempt will be made later to explain these anomalies, but for the present interpretation it follows that no values can be assigned to " $i$ " or " $l$ " unless " $p 2 l$ " is estimated significantly.

Among females, " $j$ ", the additive $\times$ dominance interaction, is significantly negative in the later stages of growth and in the final 20-week weight. But in males negative values of " $j$ " in the growth periods between 8 and 16 weeks, culminating in a significant negative value in 16 weeks weight, are counteracted by a positive value in the 16 to 20 -week growth period, so that the interaction disappears for the 20 -week weight analysis. In the female results " $p l$ " is significant and negative only in the 12- to 20-week weight increment. In this period " $p i+p l$ " is non-significantly negative and " $p^{2} i-p^{2} l$ " significantly positive, so that while " $l$ " is negative " $i$ " is possibly positive and certainly not negative, so that the large difference between " $m+h+l$ " and " $m+i$ " must be due to a large positive value of " $h$ " as found in the unsatisfactory earlier analysis. In the results for 8-week male weight the pattern is not dissimilar, " $p 2 l$ " and " $p i+p l$ " being significantly negative and " $p^{2} i-p^{3} l$ " non-significantly positive. Although here it is possible that " $i$ " is negative, clearly the major effect is a negative " $l$ ", the dominance $x$ dominance interaction, and hence through the large value of " $m+h+l$ " a large and positive " $h "$ as in the earlier analysis. But in the growth periods of males beyond 12 weeks " $p i+p l$ " and " $p l$ " are both significantly positive so that they become lost from the weight-for-age data, until at 20 weeks " $h$ ", the dominance deviation, is the only remaining genetic effect.

The best interpretation of the parameter estimates can then be summarised thus. A large positive value of " $h$ " with a smaller negative value of " $l$ " that is a combination of overdominance and duplicate interaction (Jinks and Jones, 1958), exist throughout the female data and in the younger male weights. Negative values of " $j$ ", the additive $\times$ dominance interaction, appear in the control of 20-week weight in females and 16-week weight in males. However, between 16 and 20 weeks in males, both the effects of both " $l$ " and " $j$ " are reversed so that by 20 weeks males exhibit simple overdominance.

In much quantitative genetics research there is an implicit, or sometimes 
explicit (e.g. Butler, 1952; Morton and O'Donald, 1962), assumption that genetic control of metric traits is similar in the two sexes, sex differences being caused by a simple proportional effect of sex on otherwise identical genetic effects. The results of this paper, among several others (e.g. Breese and Mather, 1960; Jinks and Broadhurst, 1963; Morton, 1970) suggest this assumption is invalid. In retrospect, the assumption seems not even reasonable, for if there is interaction between different genes and between sex and genetic effects in the control of metric traits, it is likely that the development of sex differentials during evolution will have been accompanied by the development of different genetic interactions in controlling the traits in each sex. It is also likely that the form of genetic control in each sex will be related to the role of that sex.

We have argued previously (Morton, 1970) that the opposition of sign in " $h$ ", the dominance deviation, and " $l$ ", the dominance $\times$ dominance interaction, is an expression of homeostatic genetic control, in that it causes genotypes of varying degrees of heterozygosity to have similar means, and hence shows little variation in an outbred population. It may be that too great a uniformity of males in a polygamous species such as the chicken is a disadvantage and that the reversal of genetic control as cocks approach maturity removes the earlier homeostatic control, allowing further variation to be expressed and possibly making the selection of the dominant cock a quicker and easier process.

Throughout the above discussion of the digenic interaction terms, " $p^{4} l-2 p^{3} l$ " which was one of the most significant in the analyses was ignored. This was because although " $p$ " must be less than one-half, it appeared in this analysis, as in that of Jinks and Perkins (1969) on height in Nicotiana, that the terms of digenic interaction containing the higher powers of " $p$ " had the greater estimates. A diagnostic for the presence of linkage is the failure of models without linkage to fit the observed rate of inbreeding depression, particularly in the present case from the $\mathrm{S}_{2}$ to the $\mathrm{S}_{8}$. An alternative or additional cause of this inbreeding depression could be residual genetic segregation in the parental inbred lines. The amount of inbreeding that the $C H$ and $I A$ lines of chicken had undergone, the extent of the heterosis observed when they were crossed and the increased variation of the segregating generations over the pure lines and $S_{1}$ 's, all suggest that the lines were largely homozygous for genes affecting body weight. But Gilmour (1959) had shown that these lines continued to segregate at several blood group loci. If some of the genes controlling body weight continued to segregate linked with these blood groups the anomalies in the estimates of " $p^{4} l-2 p^{3} l$ " and other of the linked digenic interaction parameters might be explained. A similar explanation of Jinks and Perkins' (1969) results at first seems improbable in view of the statement of Mather and Vines (1952) on the lines which they used that "no suggestion has ever appeared that the parental lines were anything but true breeding". But considering the amount of heterosis observed in height and early flowering by Jinks and Perkins, it seems not impossible that some loci were maintained segregating.

If this is the right explanation of the anomalous results, it points in one respect to the same conclusion as the main analysis. The blood group loci found segregating by Gilmour (1959) were the $B, C, L$ and $\mathcal{N}$ loci in the $C H$ line and the $A-E$ and $B$ loci in the $I A$ line. Scheinberg (1956 and quoted in Gilmour (1960)) found a linkage relationship involving the $B$ locus. Briles 
(1963) found probable linkage relationships involving the $A-E$ and $C$ loci and possibly also the $L$ locus. The majority of the many chromosomes of the chicken $(2 n=78)$ are extremely small (Owen, 1965). Thus both the evidence of the importance of linkage relationships in the inheritance of body size and the explanation of the anomalous results as due to continued segregation linked to blood groups suggest that genetic control of body size mainly resides in the few large chromosomes.

Acknowledgments. - I wish to record my thanks to the following persons and organisations: to the Cambridge University Computer Laboratory for the use of the Titan Computer; to Mr Robert Marrs for aid with programming; to Mr Barrie Wright and the late Mr Arthur Smith for technical help; to the Agricultural Research Council for financial aid in the maintenance of the chickens; and particularly to Dr D. G. Gilmour for his generous help and advice.

\section{REFERENCES}

BREese, E. L., AND MATHER, K. 1960. The organisation of polygenic activity within a chromosome in Drosophila. Heredity, 14, 375-390.

BRILES, w. E. 1963. Current status of blood groups in domestic birds. Z.F. Tierz. $u$. Ziichtungsb., 79, 371-391.

bucio ALANIs, L., PERKINs, J. M., AND JINKs, J. L. 1969. Environmental and genotype-environmental components of variation. V. Segregating generations. Heredity, 24, 115-127.

BUTLER, L. 1952. A study of size inheritance in the house mouse. II. Analysis of five preliminary crosses. Canad. J. Zool., 30, 154-171.

BUVANENDRAN, v. 1967. Performance of breeds and breed crosses of broiler parents. Trop. Agriculturist (Ceylon), 123, 1-6.

CARTE, 1. F., AND SIEGEL, P. B. 1970. Scaling effects and the inheritance of juvenile body weight in chickens. Can. 7. Genet. Cytol., 12, 724-727.

CAVALLI, I. L. 1952. An analysis of linkage in quantitative inheritance. Quantitative Inheritance, pp. 135-144. H.M.S.O., London.

Cock, A. G. 1953. The interpretation of autosexing. F. Genet., 51, 421-233.

COCK, A. G., AND MORTON, J. R. 1963. Maternal and sex-linked effects on size and conformation in domestic fowl. Heredity, 18, 337-350.

GILMOUR, D. G. 1959. Segregation of genes determining red cell antigens at high levels of inbreeding in chickens. Genetics, 44, 14-33.

gllmour, D. G. 1960. Blood groups in chickens. Brit. Poult. Sci., 1, 75-100.

HAYMAN, B. 1. 1953. Components of variation under sib-mating. Heredity, 7, 121-125.

HAYMAN, B. I. 1958. The separation of epistatic from additive and dominance variation in generation means. Heredity, 12, 371-390.

JINKS, J. L., AND BROADHURST, P. L. 1963. Diallel analysis of litter size and body weight in rats. Heredity, 18, 319-336.

JNKS, J. L., AND JONEs, R. M. 1958. Estimation of components of heterosis. Genetics, 43, 223-234.

JINks, J. L., AND PERKINs, J. M. 1969. The detection of linked epistatic genes for a metrical trait. Heredity, 24, 465-475.

MATHER, x. 1949. Biometrical Genetics. Methuen \& Co., Limited, London.

MATHER, X., AND JINKs, J. L. 1963. Correlations between relatives arising from sex-linked genes. Nature, 198, 314-315.

MATHER, K., AND VINEs, A. 1952. The inheritance of height and flowering time in a cross of Nicotiana rustica. In Quantitative Inheritance. H.M.S.O. London.

MORTON, J. R. 1964. Gene action and interaction in the control of metric traits in chickens and mice. Heredity (Abstr.), 19, 171.

MORTON, J. R. 1970. Analysis of gene action in the control of body weight and tail length in the mouse. Heredity, 25, 555-574.

MORTON, J. R., AND o'Donald, P. 1962. Analysis of gene action from inbred line crosses in non-self-fertilising organisms. Heredity, 17, 553-559.

OWEN, J. T. T. 1965. Karyotype studies on Gallus domesticus. Chromosoma (Berl.), 16, 601-608. 
PEASE, M., ANd Dudley, F. 1954. Hybrid vigour in poultry. Rep. Proc. Xth World Poult. Congr., 2, 45-49.

SCHEINBerG, s. L. 1956. Genetic studies of cellular antigens in the fowl. Genetics, 38, 843844.

VAN DER VEEN, J. H. 1959. Tests of non-allelic interaction and linkage for quantitative characters in generations derived from two diploid pure lines. Genetica, 30, 201-232. 